\title{
THE CORRELATION BETWEEN AWARENESS AND ATTITUDE DOMAINS ON URINARY TRACT INFECTION (UTI) AMONG BURAPHA UNIVERSITY STUDENTS IN CHONBURI, THAILAND
}

\author{
Neni Widiasmoro Selamat ${ }^{1}$, Kenneth Paul Martinez ${ }^{1}$, Gaiyathre Subrain ${ }^{1}$ and Titinun Auamnoy ${ }^{2}$ \\ ${ }^{1}$ Department of Diagnostics and Allied Health Sciences, Faculty of Health and Life Sciences, Management and Science \\ University, 40100 Shah Alam, Selangor, Malaysia \\ ${ }^{2}$ Faculty of Pharmaceutical Sciences, Burapha University, 20131 Chonburi, Thailand
}

Corresponding author: Neni Widiasmoro Selamat

Email: neni_widiasmoro@msu.edu.my

\begin{abstract}
A study was done to describe awareness, knowledge and attitude level on Urinary Tract Infection among university students of Burapha University, Thailand. Cross-sectional study was conducted with the use of self-modified questionnaire consisting of socio-demographic questions and AKA domains. Total of 91 respondents (male students $n=13$ and female $n=76$ ) aged 19 years old participated. The total AKA level was found to be in high category $(75.86 \pm 13.81)$ and between the domains, Attitude (70.00 \pm 13.28$)$ is categorized as positive, followed by both Knowledge (57.24 \pm 15.94) and Awareness (39.37 \pm 13.01) which is categorized as moderate. Correlation between Awareness-Attitude was found significant at $p=0.003$. After the adjustment of covariates, female gender was found to have the strongest relationship compared to other covariates and all independent factors combined accounted $14.8 \%$ of variability in Total $A K A$. The sociodemographic factors' of the students influenced the level of AKA and female gender have found to have be best predictor for Total AKA on UTI. Thus, this research has provided ample findings to further formulate an educational tool for the public.
\end{abstract}

Keywords: Awareness, Knowledge, Attitude, Urinary Tract Infection, Adolescents

\section{INTRODUCTION}

The process of expulsion of urine from the bladder is known as urination ${ }^{1}$. The stream of urine from the bladder helps wash away any microorganisms which could invade an otherwise sterile urinary tract ${ }^{2}$. Hence, urinary tract infection (UTI) is defined as a microbial infiltration of the urinary tract system ${ }^{3,4}$. Some of the factors such as poor personal hygiene ${ }^{5}$ or sexual intercourse would cause the organisms to travel up the urethra and may likewise contaminate the urinary bladder ${ }^{6,7}$.

Eventually, when infection in urinary system is not treated, infected individuals may only show rather vague symptoms ${ }^{8}$ and may cause numerous of complications shortly. Some of the complications such as infection of the urethra (known as urethritis), bladder (known as cystitis), prostate (known as prostatitis) and kidney known as pyelonephritis are some of the most common complications in the case of UTI ${ }^{3,9}$.

Globally, the case of untreated UTI has been a significant factor of morbidity for various age groups and genders ${ }^{10-14}$. Every year, there an estimation of 150 million people were diagnosed with this infection ${ }^{15,16}$ In a neighboring country of Thailand, previous study done in Malaysia found that the pervasiveness of lower urinary tract manifestations among men matured 40 and above was found at $42.7 \%$ in which the severity of LUTS was analyzed concerning their age group ${ }^{17}$.
Due to asymptomatic infection, the case of UTI at a younger age are more dangerous despite occurring in all age group ${ }^{2}$. Besides that, there are limited number of studies regarding UTI that was done on this population but according to previous studies that have been done by Selekman, Allen, \& Copp (2016), Srivastava (2018) and 19 the findings of their studies shows high prevalence of UTI among adolescent population.

On the other hand, AKA survey-based studies were done several time in Thailand but none of these previous literatures have covered AKA survey study on UTI. Some of the survey that have been done on Thailand population were; Knowledge, attitudes and perceptions of Parkinson's Disease ${ }^{20}$ and study of knowledge and attitude improvement on epilepsy ${ }^{21}$. However, the findings of these studies showed that the outcome of AKA levels was found to be varied between communities, population and countries.

Therefore, the difference of outcomes between these studies shows that different population and background possesses different outlook and level of AKA on a particular disease or condition. Hence, the AKA part of this study is a crucial and vital tool to obtain accurate information of the Thailand adolescent populations' AKA on UTI.

Thus, this study aimed to be the first to describe 
and give a preparatory understanding into the awareness, knowledge and attitude (AKA) of the Burapha University students, Chonburi Thailand regarding urinary tract infection (UTI). The assessment would include the general level of AKA and the association of the socio-demographic factors of the respondents with their AKA level as well as the correlation between AKA domains.

\section{METHODS}

\section{Study design and sample selection}

This cross-sectional study was carried out in Burapha University, Chonburi Thailand among 19 years old students from Faculty of Education. These repondats were selected for convenient sampling since 19 years old age group are still within adolescent's age range. The respondent was chosen through non - probability sampling technique and this is due to the time limitation and cost - effectiveness of the study, It was conducted over two months from early November until the end of December 2018.

\section{Data collection procedure}

The study was conducted following the Declaration of Helsinki, and the protocol was approved on 7 June 2019 by The Ethic Committee of Burapha University, Chonburi Thailand (Number: 3/2562). First of all, some of the approvals that was acquired before the study was done including approvals from Faculty of Education, Burapha University. Then, potential respondents were selected based on the inclusion criteria that was set; [1] student aged 19 years old registered at Faculty of Education, Burapha University and [2] student that understand either Thai language or English were set to be the inclusion criteria. In contrast, the exclusion criteria for the respondents were: [1] student not aged 19 years old and not registered at Faculty of Education, Burapha University and [2] student that does not understand neither Thai language or English.

\section{Instrument}

Self-modified questionnaire that consists of closed ended questions was used in this study as the instrument. It was used to collect relevant data to meet the research objectives that was set. This questionnaire made up of two sections; respondents' sociodemographic section and AKA domains section. First, the respondents' sociodemographic section composed of social demographic information; age, gender, residential area and race while the other section consists of Awareness, Knowledge and Attitude (AKA) on urinary tract infection (UTI). Since there have not been any AKA questionnaire on UTI validated and established before, some parts of this questionnaire were adapted and modified from previous questionnaires ${ }^{22,23}$. In the AKA section, Part One consists of total 7 questions that measures the awareness level of the respondents in the form of Visual Analogue Scale (VAS) ${ }^{24}$. On the other hand, Part Two recorded the respondents' knowledge on UTI based on 20 questions in which the respondents needs to answer either; "YES" or "NO" or "NOT SURE" while Part Three documented 10 attitude statements which was also in the form of Visual Analogue Scale (VAS). Therefore, a total of 37 questions were included in the questionnaire form. For this study, the questions in the research instrument was translated into Thai ${ }^{25}$ language for local use. The translation process underwent two phases to maintain the content of the research items. Finally, there were also validation process, which composed of six steps; establish face validity, pilot test, and clean data set, principle components analysis and Cronbach's Alpha which was done by the experts.

\section{Statistical analysis}

For data analysis purposes, this study utilized the Statistical Package for Social Sciences (Version 23.0). Some parts of the socio-demographic information were investigated descriptively and were displayed as frequencies and percentages. Then, the normality test was also done to test the data dispersion of the variables before the employment of other statistical tests. General AKA level was exhibited descriptively as mean and standard deviation. On the other hand, an Independent t-test was run to test score comparisons of several group for the AKA level based on the socio-demographic factors; gender and residential. In addition, Pearson Correlation test was used to study the relationship between the domains; Awareness, Knowledge and Attitude.

\section{RESULTS}

\section{Socio-demographic characteristics}

A total of 91 respondents (male students $n=13$ and female students $n=76$ ) aged 19 years old participated in this study. All of the respondents included were Thailanders with majority of them resided in an urban area (52.7\%) and only (37.4\%) from rural area. Further details are shown in Table 1. 
Table 1: Distribution of respondents according to the socio-demographic data among Burapha University students in Thailand

\begin{tabular}{llll}
\hline Variables & Categories & Frequency & Percentage (\%) \\
\hline Gender** $^{*}$ & Male & 13 & 14.3 \\
& Female & 76 & 83.5 \\
Residential Area** & Urban & 48 & 52.7 \\
& Rural & 34 & 37.4 \\
\hline
\end{tabular}

${ }^{* *}$ Contains missing data $(n \neq 91)$ thus total percentage $\neq 100 \%$

\section{General AKA}

The score range of the study was set ranging from 0.0 - 100 after the total score of each domain was converted to a percentage (\%). Generally, total AKA level of the Burapha University students is found to be in high category (75.86 \pm 13.81). Among the three domains, Attitude (70.00 \pm 13.28) was found to have the most astounding mean which is categorized as positive attitude, took after both Knowledge (57.24 \pm 15.94$)$ and Awareness (39.37 \pm 13.01) which is categorized as moderate knowledge and awareness respectively. Based on the mean score of each domain, respondents are suggested to have positive attitude with moderate knowledge and awareness regarding urinary tract infections. Further details were shown in Table 2.

Table 2: Overall Awareness, Knowledge, Attitude and Total AKA level among Burapha University students in Thail:nd

\begin{tabular}{lllll}
\hline Domain & Mean & $\begin{array}{l}\text { Standard } \\
\text { Deviation }\end{array}$ & Score Range & Interpretation \\
\hline Awareness & 39.37 & 13.01 & $0-100$ & Moderate \\
Knowledge & 57.24 & 15.94 & $0-100$ & Moderate \\
Attitude & 70.00 & 13.28 & $0-100$ & Positive \\
Awareness, & 54.98 & 9.32 & $0-100$ & Moderate \\
Knowledge \& & & & & \\
Attitude (AKA) & & & & \\
\hline
\end{tabular}

*Descriptive statistics

*Low / Negative : $\quad<33.33$

*Moderate / Indifferent : : $\quad: 33.34-66.66$

*High / Positive : $>66.67$

AKA level comparisons based on socio-demographic characteristics

a. Gender

Female respondents are found to have slightly better Awareness (39.96 \pm 13.17$)$ and Knowledge (57.75 \pm 15.95$)$ compared to male's Awareness $(36.42 \pm 11.06)$ and Knowledge $(55.00 \pm 16.71)$ respectively. On the other hand, male respondents scored slightly better Attitude (75.72 \pm 11.76).
Total AKA $(55.15 \pm 11.03)$ compared to female's Attitude (69.28 \pm 13.01) and Total AKA (55.11 \pm 9.05) respectively. However, as shown in Table 3 , the mean differences for both gender on all of these domains were insignificant.

Table 3: Differences in AKA level based on gender among Burapha University students in Thailand

\begin{tabular}{|c|c|c|c|c|c|c|}
\hline \multirow[t]{2}{*}{ Domain } & \multicolumn{2}{|c|}{ Male $(n=13)$} & \multicolumn{2}{|c|}{ Female $(n=76)$} & \multirow[t]{2}{*}{$95 \% \mathrm{Cl}$} & \multirow[t]{2}{*}{ p-value } \\
\hline & Mean & SD & Mean & SD & & \\
\hline Awareness & 36.42 & 11.06 & 39.96 & 13.17 & $-11.24,4.14$ & 0.363 \\
\hline Knowledge & 55.00 & 16.71 & 57.75 & 15.95 & $-12.33,6.83$ & 0.570 \\
\hline Attitude & 75.72 & 11.76 & 69.28 & 13.01 & $-1.23,14.09$ & 0.990 \\
\hline $\begin{array}{l}\text { Awareness, } \\
\text { Knowledge } \\
\text { Attitude (AKA) }\end{array}$ & 55.15 & 11.03 & 55.11 & 9.05 & $-5.53,5.62$ & 0.987 \\
\hline
\end{tabular}

* Independent $t$-test 


\section{b. Residential Area}

Respondents from urban area scored slightly better Awareness (40.87 \pm 12.80$)$, Knowledge $(58.73 \pm 14.83)$ and Total AKA (55.83 \pm 8.91) compared to rural respondents' Awareness (37.50 \pm 13.46), Knowledge $(55.44 \pm 18.51)$ and Total AKA $(54.18 \pm 10.41)$ respectively. On the other hand, respondents from rural areas are found to have slightly better Attitude (71.24 \pm 13.82) compared to urban respondents' Attitude $(69.57$ \pm 12.92 ) respectively. However, as shown in Table 4, the mean differences for both residential areas on all of these domains were insignificant.

Table 4: Differences in AKA level based on residential area among Burapha University students in Thailand

\begin{tabular}{|c|c|c|c|c|c|c|}
\hline \multirow[t]{2}{*}{ Domain } & \multicolumn{2}{|c|}{ Urban $(n=48)$} & \multicolumn{2}{|c|}{ Rural $(n=34)$} & \multirow[t]{2}{*}{$95 \% \mathrm{Cl}$} & \multirow[t]{2}{*}{ p-value } \\
\hline & Mean & SD & Mean & SD & & \\
\hline Awareness & 40.87 & 12.80 & 37.50 & 13.46 & $-2.46,9.20$ & 0.254 \\
\hline Knowledge & 58.73 & 14.83 & 55.44 & 18.51 & $-4.05,10.63$ & 0.375 \\
\hline Attitude & 69.57 & 12.92 & 71.24 & 13.82 & $-7.59,4.27$ & 0.579 \\
\hline $\begin{array}{l}\text { Awareness, } \\
\text { Knowledge } \\
\text { Attitude (AKA) }\end{array}$ & 55.83 & 8.91 & 54.18 & 10.41 & $-2.61,5.91$ & 0.444 \\
\hline
\end{tabular}

\section{c. Correlation between Awareness, Knowledge} and Attitude domains

A correlation test was done between three domains with linear regression. Table 5 shows that the correlation between Awareness and Attitude is significant at $p=0.003$. The state of positive linear correlation is weak between Awareness and Attitude at 0.283 with $R^{2}$ of 0.08 . That being said, the total percent variance of Attitude can be explained by $8 \%$ of the variance of the Awareness score.

\section{d. Relationship between Awareness, Knowledge and Attitude domains}

From the univariate analysis, several sociodemographic factors; age $(r=0.203)$, female gender $(r=0.263)$ and Indian race $(r=-0.233)$ were found to be statistically significant $p<0.05$
(Table 6A). Then, multiple regression analysis (MRA) further shows that when compared to male gender, female gender significantly predicted higher Total AKA regarding UTI $(B=0.216, p<$ $0.05)$ while among the race, Indian was found to be significantly predicted lower Total AKA regarding UTI $(B=-0.177, p<0.05)$ when compared to Malay (reference group). Hence, after covariate adjustment using MRA, female gender was found to have the strongest relationship compared to other covariates (Table 6B). All independent factors combined accounted for $14.8 \%$ of the variability in Total AKA regarding urinary tract infection and no multicollinearity was found.

Table 5: Pearson Correlation between Awareness, Knowledge and Attitude domains ( $n=91)$ among Burapha University students in Thailand

\begin{tabular}{llll}
\hline Correlation, $r$ & & & \\
\hline & Awareness & Knowledge & Attitude \\
\hline Awareness & 1 & & \\
Knowledge & 0.142 & 1 & \\
Attitude & $* 0.283$ & 0.099 & 70.00 \\
\hline Mean & 39.37 & 57.24 & 13.28 \\
Standard Deviation & 13.01 & 15.94 &
\end{tabular}


Table 6a: Pearson Correlation between Awareness, Knowledge and Attitude domains $(n=91)$ on UTI among Burapha University students in Thailand

\begin{tabular}{|c|c|c|c|c|c|c|c|c|}
\hline \multicolumn{9}{|c|}{ Correlation $(r)$} \\
\hline \multirow{8}{*}{$\begin{array}{l}\text { Pearson } \\
\text { Correlation }\end{array}$} & & $\begin{array}{l}\text { Total } \\
\text { AKA }\end{array}$ & Age & Female & Rural & Chinese & Indian & $\begin{array}{l}\text { Other } \\
\text { Races }\end{array}$ \\
\hline & $\begin{array}{l}\text { Total } \\
\text { AKA }\end{array}$ & 1 & & & & & & \\
\hline & Age & ${ }^{*} 0.203$ & 1 & & & & & \\
\hline & Female & ${ }^{*} 0.263$ & 0.120 & 1 & & & & \\
\hline & Rural & 0.029 & -0.063 & -0.138 & 1 & & & \\
\hline & Chinese & 0.135 & 0.003 & 0.093 & -0.021 & 1 & & \\
\hline & Indian & $*_{-} 0.233$ & -0.133 & -0.133 & -0.037 & -0.026 & 1 & \\
\hline & $\begin{array}{l}\text { Other } \\
\text { Races }\end{array}$ & 0.055 & 0.051 & 0.093 & -0.021 & -0.015 & -0.026 & 1 \\
\hline
\end{tabular}

${ }^{*}$ Significant level set at $p<0.05$

Table 6b: Pearson Correlation between Awareness, Knowledge and Attitude domains $(n=91)$ on UTI among Burapha University students in Thailand

\begin{tabular}{llllll}
\hline Variables & $\begin{array}{l}\text { Unstandardized } \\
\text { Coefficients }\end{array}$ & $\begin{array}{l}\text { Standard } \\
\text { Error }\end{array}$ & $\begin{array}{l}\text { Standardized } \\
\text { Coefficients }\end{array}$ & $\mathrm{t}$ & $p$-value \\
\hline Age & 1.260 & 0.670 & 0.156 & 1.882 & 0.062 \\
Female & 4.687 & 1.817 & 0.216 & 2.580 & 0.011 \\
Rural & 4.024 & 5.087 & 0.065 & 0.791 & 0.430 \\
Chinese & 9.676 & 7.084 & 0.112 & 1.366 & 0.174 \\
Indian & -9.022 & 4.209 & -0.177 & -2.144 & 0.034 \\
Other Races & 2.191 & 7.089 & 0.025 & 0.309 & 0.758
\end{tabular}

a. Dependent Variable : Total Awareness, Knowledge and Attitude (AKA)

\section{DISCUSSION}

Previous studies that were done in regards to urinary tract infection were limited to the study of prevalence and have not been any study regarding their level of Awareness, Knowledge and Attitude on this particular infection. That being said, there has not been any study done on any populations in Thailand as well. There have been several AKA survey studies done in Thailand however, these papers were done on different infections and interests ${ }^{26,27}$. Nevertheless, the findings of these papers suggested the need to improve the level of AKA on their interest infection.

Given that there has been no previous study of AKA level on UTI, this finding would be known to be the first insight of adolescents' awareness, knowledge, attitude and possible relationship between the domains on this infection. The findings presented in the current study involving the adolescent population's general AKA level towards UTI were found to be generally moderate (mean \pm 54.98). Similarly, both their Awareness (mean \pm 39.37 ) and Knowledge (mean \pm 57.24) level were also moderate. The moderate and category have a mean score ranging from 33.34 to 66.66 .
The reason behind a moderate level of Awareness, Knowledge and Total AKA can be explained based on the fact that all the respondents are a 19 years old Foundation in Science students of Burapha University, Chonburi. The fact that the respondents most probably have had studied UTI or UTI-related topics in their syllabus may have been the main reason that majority of the level of each domain was moderate. To further explain and compare this finding, an AKA survey was done among 844 Thai university students regarding HIV/AIDS prevention and the results showed an excellent high level of all domains; knowledge, attitude and self-awareness ${ }^{28}$.

In addition, among the domain which has possessed the highest score was the Attitude of the respondents. A high score was achieved by the respondents on their Attitude domain would be because both Awareness and Knowledge domain has recorded a moderate level. A similar trend of results whereby Attitude was found to be positive (high) and both Awareness and Knowledge were found moderate was also recorded by a study done among government secondary school students in Shah Alam, Malaysia regarding their AKA level on the use of antibiotics ${ }^{29}$. Therefore, 
there is a strong possibility of a positive relationship between the domains.

That being said, based on the correlation test that was done on the AKA domains showed a positive but weak linear correlation between Awareness and Attitude at 0.283 with $\boldsymbol{R}^{2}$ of 0.08 . It means that the total percent variance of Attitude can be explained by $8 \%$ of variance of the Awareness score. This would explain the relationship between the domains of this study, a positive correlation was found therefore the moderate level of Awareness and Knowledge among the respondents may have predicted a high level of Attitude.

Besides that, the relationship found between the domains in this study can be explained from previous study done among secondary school students in Malaysia on environment education. The study found out that there is a strong relationship observed between awareness and attitude among the respondents. Hence, same interpretation can be made of both awareness and knowledge domains in this study which further predicted a better level of attitude regarding UTI 30. Thus, this finding could validate the importance and relevance of AKA study on any diseases and infections, especially UTI as it would show the relationship between the domain.

However, in regards to the association between the respondents' sociodemographic factor with their AKA level, there was no statistically significant difference observed on both gender and their residential area. Therefore, the null hypothesis of the study regarding the association between sociodemographic factor with AKA level is accepted; there are no significant differences between them.

\section{CONCLUSION}

The moderate to high/positive level of AKA domains among students of Burapha University, Chonburi may still demonstrate room for improvement regarding UTI. This would definitely promote relevance as well as significance to organizations and services that would benefit from the study. Even though the current level of adolescents' attitude towards UTI is positive but an intervention study which may involve IT-based UTI education tool can be suggested for the aim of improving the other domains such as the awareness and knowledge. This should represent the next focus of the future study which involves testing health educational methods that would aid the population on this matter.

\section{ACKNOWLEDGEMENTS}

Our team would like to give thanks to Management and Science University (MSU) for their financial support (MSU Seed Research Grant; SG-406-1217-HLS). We would also like to acknowledge and thank all institutions that involved in the process; Research Management Centre (RMC), MSU Shah Alam, Malaysia and Faculty of Education in Burapha University, Chonburi for giving us the chance to do the research.

\section{CONFLICT OF INTEREST}

We wish to confirm that there are no known conflicts of interest associated with this publication and there has been no significant financial support for this work that could have influenced its outcome. We confirm that the manuscript has been read and approved by all named authors and that there are no other persons who satisfied the criteria for authorship but are not listed. We further confirm that the order of authors listed in the manuscript has been approved by all of us. We further confirm that any aspect of the work covered in this manuscript that has involved either experimental animals or human patients has been conducted with the ethical approval of all relevant bodies and that such approvals are acknowledged within the manuscript.

\section{FUNDING}

This study was funded by Management and Science University (MSU) - (MSU Seed Research Grant; SG-406-1217-HLS).

\section{ETHICAL APPROVAL}

All procedures performed in studies involving human participants were in accordance with the ethical standards of the institutional and/or research committee and with the 1964 Helsinki declaration and its later amendments or comparable ethical standards. The study was conducted in accordance with the Declaration of Helsinki, and the protocol was approved on 7 June 2019 by The Ethic Committee of Burapha University, Chonburi Thailand (Number: 3/2562).

\section{REFERENCES}

1. Marieb EN, Hoehn K. Human Anatomy Eamp; Physiology. 10th ed. Harlow, United Kingdom: Pearson; 2015. 1261 p.

2. VanMeter KC, Hubert RJ. Microbiology for the Healthcare Professional, 2nd ed. Maryland Heights, Missouri: Elsevier Inc.; 2010. 296-302 p.

3. Barber AE, Norton JP, Spivak AM, Mulvey MA. Urinary Tract Infections: Current and Emerging Management Strategies. Clin Infect Dis 2013;57(5):719-24.

4. Fatima SS, Mussaed E Al. Urinary Tract Infection. In Springer, Singapore 2018:122. 
5. Gondim R, Azevedo R, Braga AANM, Veiga ML, Barroso Jr. U, Gondim R, et al. Risk factors for urinary tract infection in children with urinary urgency. Int braz $j$ urol 2018;44(2):378-83.

6. Engelkirk Paul G., Duben-EngelkirkJanet L., Gwendolyn R., Burton Wilson. Burton's Microbiology for the Health Sciences .9th ed. Philadelphia, Pa.: Wolters Kluwer.; 2011. 297-299 p.

7. Winberg J, Andersen HJ, Bergström T, Jacobsson $B$, Larson $H$, Lincoln $K$. Epidemiology of Symptomatic Urinary Tract Infection In Childhood. Acta Paediatr 1974;63(s252):1-20.

8. Williams A, Jacobsen A. Pediatric and Adolescent Gynecology : Urinary Problems in Pediatric and Adolescent Gynecology Practice .Cambridge University Press; 2018: $172 \mathrm{p}$

9. Beyene G, Tsegaye W. Bacterial Uropathogens in Urinary Tract Infection and Antibiotic Susceptibility Pattern in Jimma University Specialized Hospital, Southwest Ethiopia. Ethiop J Health Sci $201 ; 21(2): 141-6$

10. Michaud JE, Gupta N, Baumgartner TS, Kim B, Bosemani T, Wang M-H. Cost and radiation exposure in the workup of febrile pediatric urinary tract infections. J Surg Res 2016;203(2):313-8.

11. Flores-Mireles $\mathrm{AL}$, Walker JN, Caparon $\mathrm{M}$, Hultgren SJ. Urinary tract infections: epidemiology, mechanisms of infection and treatment options. Nat Rev Microbiol 2015;13(5):269-84

12. Becknell B, Schober M, Korbel L, Spencer JD. The diagnosis, evaluation and treatment of acute and recurrent pediatric urinary tract infections. Expert Rev Anti Infect Ther 2015;13(1):81-90.

13. Spencer JD, Schwaderer A, McHugh K, Hains DS. Pediatric urinary tract infections: an analysis of hospitalizations, charges, and costs in the USA. Pediatr Nephrol 2010;25(12):2469-75.

14. AL Freedman. Urologic diseases in North America Project: trends in resource utilization for urinary tract infections in children. J Urol 2005;(3):949-954.

15. Akram M, Shahid M, Khan AU. Etiology and antibiotic resistance patterns of community-acquired urinary tract infections in J N M C Hospital Aligarh,
India. Ann Clin Microbiol Antimicrob 2007;6(1):4.

16. Harding GKM, Ronald AR. The management of urinary infections; what have we learned in the past decade? Int $J$ Antimicrob Agents 1994;4(2):83-8.

17. Ho CCK, Ho C, Goh EH, Singam P, Tan GH, Bahadzor B, et al. Prevalence and awareness of lower urinary tract symptoms among males in the outpatient clinics of University Kebangsaan Malaysia Medical Centre. J Mens health 2011;8(3):208-208.

18. Srivastava S. International journal of reproduction, contraception, obstetrics and gynecology. Vol. 7, International Journal of Reproduction, Contraception, Obstetrics and Gynecology 2018. 1385$1388 \mathrm{p}$

19. Selekman RE, Allen IE, Copp HL. Determinants of practice patterns in pediatric UTI management. J Pediatr Urol 2016;12(5):308.e1-308.e6.

20. Jitkritsadakul O, Boonrod N, Bhidayasiri R. Knowledge, attitudes and perceptions of Parkinson's disease: A cross-sectional survey of Asian patients. J Neurol Sci 2017;374:69-74

21. Locharernkul C, Suwaroporn S, Krongthong W, Limarun C, Arnamwong A. A study of knowledge and attitude improvement on epilepsy among Thai physicians and nurses. J Med Assoc Thai 2010;93(8):875-84.

22. Neni SW, Latif AZA, Wong SY, Lua PL. Awareness, knowledge and attitudes towards epilepsy among rural populations in East Coast Peninsular Malaysia: a preliminary exploration. Seizure 2010;19(5):280-90.

23. Thanavanh B, Harun-Or-Rashid M, Kasuya $\mathrm{H}$, Sakamoto J. Knowledge, attitudes and practices regarding HIV/AIDS among male high school students in Lao People's Democratic Republic. J Int AIDS Soc 2013;16(1):17387.

24. Hosadurga R, Shanti T, Hegde S, Kashyap RS, Arunkumar SM. Awareness, knowledge, and attitude of patients toward dental implants - A questionnairebased prospective study. J Indian Soc Periodontol 2017 Jul 1;21(4):315-25.

25. Sadiq MB, Syed-Hussain SS, Ramanoon SZ, Saharee AA, Ahmad NI, Noraziah MZ, et al. Knowledge, Attitude and Perception 
Regarding Antimicrobial Resistance and Usage Among Ruminant Farmers in Selangor, Malaysia. Prev Vet Med 2018

26. Sartelli M, Kluger $Y$, Ansaloni L, Coccolini $F$, Baiocchi GL, Hardcastle TC, et al. Knowledge, awareness, and attitude towards infection prevention and management among surgeons: identifying the surgeon champion. World J Emerg Surg 2018;13(1):37.

27. Kietpeerakool C, Phianmongkhol Y, Jitvatcharanun K, Siriratwatakul U, Srisomboon J. Knowledge, awareness, and attitudes of female sex workers toward HPV infection, cervical cancer, and cervical smears in Thailand. Int J Gynecol Obstet 2009;107(3):216-9.

28. Durongritichai V. Knowledge, attitudes, self-awareness, and factors affecting HIV/AIDS prevention among Thai university students. Southeast Asian J Trop Med Public Health 2012;43(6):150211.

29. Neni WS, Subrain G, Shamshir Khan MSNN, Martinez KP, Auamnoy T. Awareness, Knowledge, and Attitude (AKA) of government secondary school students on the use of antibiotics in Shah Alam, Malaysia. J Public Heal. 2019;

30. Aminrad Z, Zarina S, Sayed Zakariya B, Hadi AS, Sakari M. Relationship Between Awareness, Knowledge and Attitudes Towards Environmental Education Among Secondary School Students in Malaysia. World Appl Sci J 2013;22(9):1326-33. 